Leandro de França Pereira

\title{
O Torcedor-Consumidor: Identificação com os Clubes e Barreiras para a Adoção do Programa Sócio Torcedor
}

\author{
Dissertação de Mestrado
}

Dissertação apresentada ao Programa de Pósgraduação em Administração de Empresas da PUCRio como requisito parcial para obtenção do título de Mestre em Administração de Empresas

Orientador: Prof. Luís Alexandre Grubits de Paula Pessôa Co-Orientador: Prof. Jorge Brantes Ferreira 


\section{Pontifícia Universidade Católloa

Leandro de Franca Pereira

O Torcedor-Consumidor: Identificação com os Clubes e Barreiras para a Adoção do Programa Sócio Torcedor

Dissertação apresentada como requisito parcial para obtenção do grau de Mestre pelo Programa de PósGraduação em Administração de Empresas da PUC-Rio. Aprovada pela Comissão Examinadora abaixo assinada.

Prof. Luis Alexandre Grubits de Paula Pessôa Orientador Departamento de Administração - PUC-Rio

Prof. Jorge Brantes Ferreira Co-Orientador Departamento de Administração - PUC-Rio

Prof. Paulo Cesar de Mendonca Motta Departamento de Administração - PUC-Rio

Prof. João Felipe Rammelt Sauerbronn Universidade do Grande Rio

Profa ${ }^{\text {. Mônica Herz }}$ Vice-Decana de Pós-Graduação do CCS - PUC-Rio 
Todos os direitos reservados. É proibida a reprodução total ou parcial do trabalho sem autorização da universidade, do autor e dos orientadores.

\section{Leandro de França Pereira}

Licenciado em Administração de Empresas pela UFRJ (Universidade Federal do Rio de Janeiro) em 2001. Especializado em Marketing pela COPPEAD (Instituto de Pós Graduação e Pesquisa em Administração). Executivo na área de gestão de marcas e produtos da SC Johnson desde 2001.

Ficha Catalográfica

Pereira, Leandro de França

O torcedor-consumidor: identificação com os clubes e barreiras para a adoção do programa sócio torcedor / Leandro de França Pereira ; orientador: Luís Alexandre Grubits de Paula Pessôa ; co-orientador: Jorge Brantes Ferreira. - 2014.

90 f. : il. (color.) ; $30 \mathrm{~cm}$

Dissertação (mestrado)-Pontifícia Universidade Católica do Rio de Janeiro, Departamento de Administração, 2014.

Inclui bibliografia

1. Administração - Teses. 2. Futebol. 3. Inovação. 4. Comportamento do consumidor. 5. Identificação. 6. Atitude. 7. Intenção de adoção. I. Pessôa, Luís Alexandre Grubits de Paula. II. Ferreira, Jorge Brantes. III. Pontifícia Universidade Católica do Rio de Janeiro. Departamento de Administração. IV. Título. 
Para minha esposa pelo amor e apoio nesta jornada. Para meu filho, que é minha alegria e razão de viver. Para meus pais, que me ensinaram o caminho correto a seguir. 


\section{Agradecimentos}

Aos meus orientadores Professores Luís Alexandre Grubits de Paula Pessôa e Jorge Brantes Ferreira, pela inspiração e estímulo para que este trabalho se tornasse uma realidade.

À PUC-Rio, pelos conhecimentos e aprendizados obtidos, sem os quais este trabalho não poderia ter sido realizado.

Aos meus amigos, pelo apoio, companheirismo e redes de contatos.

Aos meus pais, pela educação e amor.

Aos colegas da PUC-Rio, pelas ideias e horas de estudo compartilhadas.

Aos professores que participaram da banca examinadora.

A todos os professores e funcionários do Departamento pelos ensinamentos e ajuda oferecidos.

E a todos aqueles que de uma forma ou de outra, conscientemente ou não, me estimularam ou ajudaram durante a realização deste trabalho. 


\section{Resumo}

Pereira, Leandro de França; Pessoa, Luis Alexandre Grubits de Paula. O Torcedor-Consumidor: Identificação com os Clubes e Barreiras para a Adoção do Programa Sócio Torcedor. Rio de Janeiro, 2014. 90p. Dissertação de Mestrado - Departamento de Administração, Pontifícia Universidade Católica do Rio de Janeiro.

O conceito de inovação - compreendido não apenas como algo ligado à tecnologia, mas a toda ideia ou prática percebida como nova pelos indivíduos - é essencial para a busca de novos consumidores e, consequentemente, para o crescimento das organizações. Nesse sentido, o campo do marketing esportivo tem apresentado recentemente exemplos de inovações, como é o caso do Programa Sócio Torcedor (PST), lançado pelos clubes do futebol brasileiro. Nesta dissertação, realizou-se um estudo sobre o impacto do nível de identificação com time (IDT) do consumidor na percepção dos atributos de inovação do Programa Sócio Torcedor dos clubes de futebol, assim como quanto à percepção das barreiras para adoção do programa, a fim de identificar os efeitos sobre a atitude e a intenção de adoção do Programa Sócio Torcedor pelos consumidores. Para tal, conduziu-se uma survey, com dados coletados por meio de questionários físicos e online, tendo os dados sido analisados por meio de modelagem de equações estruturais. Os resultados obtidos sugerem que a identificação com o clube tem efeito direto e positivo na percepção de inovação do Programa Sócio Torcedor; e que identificação, vantagem relativa e valor são atributos que exercem grande influência na atitude e na intenção de adoção do Programa Sócio Torcedor pelo consumidor.

\section{Palavras-chave}

Futebol; inovação; comportamento do consumidor; identificação; atitude; intenção de adoção. 


\section{Abstract}

Pereira, Leandro de França; Pessoa, Luis Alexandre Grubits de Paula (Advisor). The Fans-Consumer: Team Identification and Barriers for Membership Program Adoption. Rio de Janeiro, 2014. 90p. MSc. Dissertation- Departamento de Administração, Pontifícia Universidade Católica do Rio de Janeiro.

The concept of innovation - not only related to technology, but known as any idea or practices that is perceived as new by people - is critical to reach new consumers and consequently for the organizations growth. In this sense, the sport marketing area has presented recently examples of innovations, as the Membership Program for Fans, launched by Brazilian soccer teams. This dissertation did a study about the impact of team identification of the fan consumer related to his perception of the innovation attributes of the Membership Programs, as well the perception related to the barriers to adopt the program, in order to identify the effects on attitude and intention to adopt the Membership Program by fan-consumers. It was conducted a survey through data collected by physical and online questionnaires. The data was analyzed via structural equations modeling. The results suggests that team identification has a direct and positive effect on the perception of innovation of the Membership Program, and that team identification, relative advantage and value are the attributes the have highest influence in the attitude and intention to adopt the program by fans-consumer.

\section{Keywords}

Soccer; innovation; consumer behavior; identification; attitude; intention to adopt 


\section{Sumário}

1. Introdução 13

1.1 Questões a investigar $\quad 15$

$\begin{array}{ll}1.2 \text { Objetivo do estudo } & 15\end{array}$

$\begin{array}{ll}1.3 \text { Relevância do estudo } & 16\end{array}$

1.4 Contribuições práticas do estudo 17

$\begin{array}{ll}1.5 \text { Delimitação do estudo } & 17\end{array}$

$\begin{array}{ll}1.6 \text { Organização do estudo } & 18\end{array}$

2. Revisão da literatura 19

2.1 Futebol: esporte e negócio 19

2.1.2 Programa sócio torcedor 23

2.2 Identificação e comprometimento no esporte 28

2.2.1Escala de identificação do espectador de esporte
(Sport Spectator Identification Scale - SSIS)

2.2.2 Escala de comprometimento psicológico com time

(Psychological Commitment to Team - PCT) 30

2.2.3 SSIS versus PCT 31

2.3 Inovação: difusão e resistência 32

2.3.1 Teoria de difusão da inovação 32

2.3.2 Resistência à Inovação 34

2.4 Formulação do modelo conceitual e hipóteses da pesquisa 36

2.4.1 Modelo proposto 36

3. Método 41

3.1 Tipo de pesquisa $\quad 41$

3.2 Operacionalização e definição das variáveis $\quad 41$

3.2.1 Definição operacional das variáveis 41

3.2.2 Procedimento de tradução e adaptação das escalas e Pré-teste $\quad 44$

3.2.3 Pré-teste do instrumento de pesquisa 44

3.3 População e amostra 45

3.3.1 População $\quad 45$

3.3.2 Amostra $\quad 45$

3.4 Coleta de Dados $\quad 45$

3.4.1 Instrumento de coleta de dados $\quad 45$

3.4.2 A Coleta de dados 46

3.5 Análise de dados $\quad 46$

3.5.1 Validade e confiabilidade $\quad 47$

3.5.2 Análise estatística $\quad 48$

3.6 Limitações do método $\quad 48$

4. Modelagem e análise de dados 50

4.1. Caracterização da amostra 50

4.2 Análises e resultados 52

4.2.1 Avaliação da identificação com o time (IDT) 52

4.2.2 Avaliação do modelo de mensuração 52 
4.2.3 Validade e confiabilidade dos construtos 53

4.2.4 Análise do modelo estrutural 59

4.2.4.1 Análise do modelo proposto 59

4.2.4.2 Teste das hipóteses de pesquisa 60

4.3 Discussão dos resultados 64

4.3.1 Influência da identificação com time 66

4.3.2 Influência dos construtos cognitivos e barreiras $\quad 67$

4.3.3 Influência da atitude 68

4.4 Análise adicional dos comentários qualitativos 68

5. Conclusões e recomendações 72

5.1 Resumo do estudo

5.2 Conclusões e implicações $\quad 74$

5.3 Implicações gerenciais $\quad 76$

5.4 Limitações $\quad 77$

5.5 Sugestões para pesquisas futuras $\quad 78$

6. Referências bibliográficas $\quad 79$

Apêndice $\quad 85$ 


\section{Lista de tabelas}

Tabela 2.1 - Torcedômetro 26

Tabela 3.1 - Escalas e Medidas Operacionais
para cada variável

Tabela 4.1: Características da Amostra 51

Tabela 4.2: Médias dos itens da escala SSIS 52

Tabela 4.3: Análise Estatística Descritiva da escala SSIS 52

Tabela 4.4: Confiabilidade e Variância Extraída 56

Tabela 4.5: Cargas Fatoriais Padronizadas $\quad 57$

Tabela 4.6: Índices de Ajuste do Modelo Proposto 60

Tabela 4.7: Coeficientes Padronizados Estimados, Hipóteses e Significâncias para o Modelo Estrutural Proposto 61

Tabela 4.8: Resumo dos Resultados dos Testes de Hipóteses 65

Tabela 4.9 - Comentários Qualitativos dos Respondentes 69 
Lista de figuras

Figura 2.1 - Modelo Proposto 37

Figura 4.1 - Modelo Proposto Inicial 59

Figura 4.2 - Coeficientes Padronizados Estimados
para o Modelo Proposto

Figura 4.3 - Modelo Proposto Ajustado 65 
Lista de quadros

Quadro 4.1: Matriz de Correlação entre Construtos 54

Quadro 4.2: Matriz de Validade Discriminante 